\title{
EFEITO DE EXTRATOS DE Allamanda blanchetti NO CONTROLE DE Alternaria brassicicola EM MUDAS DE COUVE-MANTEIGA ${ }^{1}$
}

\author{
JULIANA DE SOUZA GRANJA BARROS ${ }^{2 *}$, ERBS CINTRA DE SOUZA GOMES ${ }^{3}$, \\ LEONARDO SOUSA CAVALCANTI ${ }^{2}$
}

\begin{abstract}
RESUMO - O objetivo do presente trabalho foi avaliar o efeito do extrato de uma planta nativa da caatinga (Allamanda blanchetti) no controle do fungo Alternaria brassicicola quanto à indução de mecanismos de resistência em mudas de couve-manteiga e ação fungitóxica direta. Em condições de casa de vegetação, as mudas de couve-manteiga foram pulverizadas com os extratos de A. blanchetti extraídos a quente e a frio, nas concentrações 0,100, 500 e 1000 ppm. Avaliações da severidade da doença foram realizadas a 5, 6, 7, 8, 9 e 10 dias após a inoculação. Peroxidases foram analisadas em cinco tempos, quais sejam, 0, 24, 72, 120 e 168 horas após a pulverização das mudas com os extratos. Além disso, fora avaliado também a capacidade dos extratos a quente e a frio a 0, 100, 500 e 1000 ppm em inibir a germinação dos esporos de A. brassicicola. As concentrações de $1000 \mathrm{ppm}$ dos extratos a quente e a frio foram as mais eficientes no controle da doença. O extrato de $A$. blanchetti induziu aumento da atividade de peroxidase às 24 horas após a aplicação dos tratamentos e promoveu inibição da germinação dos esporos de $A$. brassicicola. Estes resultados indicam o potencial de $A$. blanchetti no controle de $A$. brassicicola, tanto pela ação direta quanto pela ativação de mecanismos de defesa.
\end{abstract}

Palavras-chave: Resistência induzida. Peroxidases. Atividade antimicrobiana. Brassica oleracea L.

\section{EFFECT OF THE Allamanda blanchetti EXTRACTS ON THE CONTROL OF Alternaria brassicola IN SEEDLINGS OF KALE}

\begin{abstract}
The objective of this study was to evaluate the effect of the extract from a native plant from caatinga (Allamanda blanchetti) in the control of the fungus Alternaria brassicicola, concerning to induction of resistance mechanisms in seedlings of kale and direct fungitoxic action. Under greenhouse conditions, the seedlings of kale were sprayed with extracts from $A$. blanchetti extracted at hot and at cold at concentrations of $0 ; 100 ; 500$ to $1000 \mathrm{ppm}$. Analysis of disease severity were performed at $5 ; 6 ; 7 ; 8 ; 9: 10$ days after inoculation. Peroxidases were analyzed five times $0 ; 24 ; 72 ; 120$, and 168 hours after spraying the seedlings with the extracts. Furthermore, the capacity of the hot and cold extracts was also evaluated at $0 ; 100 ; 500$, and $1000 \mathrm{ppm}$ to inhibit the germination of spores of $A$. brassicicola. The concentrations of $1000 \mathrm{ppm}$ of the hot and cold extracts were more effective in controlling the disease. The extract of $A$. blanchetti induced an increase in the peroxidase activity at 24 hours after treatment application and promote inhibition of germination of spores of A. brassicicola. These results indicate the potential from A. blanchetti to control A. brassicicola, both by direct action and the activation of defense mechanisms.
\end{abstract}

Keywords: Induced resistance. Peroxidases. Antimicrobial activity. Brassica oleracea L.

\footnotetext{
*Autor para correspondência

${ }^{1}$ Recebido para publicação em 31/03/2014; aceito em 09/04/2015.

${ }^{2}$ Instituto de Pesquisas em Substâncias Bioativas - IPESB, UNIVASF, Caixa Postal 510, 48902-300, Juazeiro (BA), Brasil; july.granja@hotmail.com.

${ }^{3}$ Instituto Federal do Sertão Pernambucano (IF SERTÃO - PE), Caixa Postal 76, 56302-320, Petrolina (PE), Brasil.
} 


\section{INTRODUÇÃO}

A couve-manteiga (Brassica oleracea L. var. acephala) é uma hortaliça arbustiva anual ou bienal, da família Brassicaceae, de grande importância na tradição culinária brasileira, pois possui alto valor nutritivo e é rica em sais minerais e vitaminas essenciais à saúde humana (LEFSRUD et al., 2007; SILVA et al., 2007; 2012; NOVO et al., 2010). Além disso, destaca-se pela sua expressão econômica. Dentre as variedades de brássicas, a couve-manteiga é a quarta mais cultivada no Brasil, com uma produção de $93.551 \mathrm{t}$, envolvendo 33.337 produtores em todo o país (IBGE, 2006).

Esta hortaliça, apesar de ser bem adaptada às condições edafoclimáticas do Brasil, pode ter sua produtividade comprometida devido a ocorrência de doenças, com destaque para a alternariose, causada pelo fungo Alternaria brassicicola (Schwn.) Wilt. (MICHEREFF et al., 2003). O controle da alternariose é realizado, em geral, por meio de pulverizações com fungicidas a base de chlorothalonil, iprodione ou mancozeb, antes ou após os primeiros sintomas (AZEVÊDO; MICHEREFF; MARIANO, 2000).

$\mathrm{O}$ uso indiscriminado de defensivos químicos no controle de doenças em plantas pode provocar a seleção de microrganismos resistentes. Tais substâncias, além de apresentarem alto custo não sempre atingem a eficiência desejada. De acordo com Moreira et al. (2002), a ampla utilização desses produtos, o desconhecimento dos riscos associados à sua utilização, o consequente desrespeito às normas básicas de segurança, a livre comercialização, a grande pressão comercial por parte das empresas distribuidoras e produtoras e os problemas sociais encontrados no meio rural constituem importantes causas que levam ao agravamento dos quadros de contaminação humana e ambiental observados no Brasil.

A redução da aplicação de agrotóxicos somente será possível se houver disponibilidade de outros compostos que apresentem menores impactos ambientais e riscos à saúde humana. Substâncias bioativas presentes em extratos vegetais representam uma importante fonte de compostos capazes de controlar doenças em plantas, tanto pela ação antimicrobiana direta quanto pela ativação de mecanismos de defesa das plantas tratada com esses compostos (BALBI-PEÑA et al., 2006).

Dentre os métodos alternativos de controle de patógenos em plantas a indução de resistência tem apresentado grande potencial. Neste método, o indutor não atua diretamente sobre o patógeno, mas estimula a planta a ativar seus mecanismos de defesa em resposta à presença do agente patogênico. Esses mecanismos podem envolver enzimas como peroxidase, ß-1, 3-glucanase, quitinase, fenilalanina amônia-liase e polifenoloxidase (CAVALCANTI; BRUNELLI; STANGARLIN, 2005).

Os extratos vegetais que possuem substâncias bioativas podem apresentar a capacidade de atuar como indutor de resistência (SANTOS et al.; 2007). Existem vários relatos do potencial de extratos de plantas nativas no controle de doenças em plantas (MASUDUZZAMAN; MEAH; RASHID, 2008; DOMINGUES et al., 2009; GOMES, 2011). As plantas da flora brasileira apresentam grande potencial como fonte de substâncias bioativas para o controle de doenças de plantas. Diante da vasta biodiversidade da caatinga e da necessidade da descoberta de novos compostos bioativos é de fundamental importância o estudo da flora dessa região, ainda pouco estudada sobre esse aspecto (NOVAIS et al. 2003).

Portanto, o presente trabalho teve como objetivo estudar o potencial dos extratos de Allamanda blanchetti, obtidos a quente e a frio, no controle do fungo Alternaria brassicicola como indutor de mecanismos de resistência em couve-manteiga e como fungicida natural, buscando reduzir o uso de agrotóxicos nesta cultura.

\section{MATERIAL E MÉTODOS}

Os experimentos foram conduzidos em casa de vegetação e em laboratório de bioquímica, localizados no Campus da Universidade Federal do Vale do São Francisco (UNIVASF), em Juazeiro (BA), no período de janeiro a maio de 2011.

\section{Obtenção dos extratos de Allamanda blanchetti}

Folhas de $A$. blanchetti foram coletadas no povoado de Caboclo, município de Afrânio (PE), situado a $8^{\circ} 47^{\prime} 88^{\prime}$ 'S e $40^{\circ} 93^{\prime} 79^{\prime \prime} \mathrm{W}$. Após a coleta as folhas foram armazenadas em sacos plásticos e levadas para o Centro de Referência para Recuperação de Áreas Degradadas da Caatinga (CRAD), da Universidade Federal Vale do São Francisco (UNIVASF), em Juazeiro (BA), para processamento.

$\mathrm{O}$ material foi etiquetado, submetido à secagem em estufa a uma temperatura de $40{ }^{\circ} \mathrm{C}$ por $72 \mathrm{~h}$ e posteriormente triturado em moinho de faca para a obtenção de um pó fino e uniforme. Para a preparação dos extratos de $A$. blanchetti foram utilizados dois métodos de extração: a quente e a frio. Na extração a quente utilizou-se um extrator Soxhlet, no qual fora processado $150 \mathrm{~g}$ do pó das folhas em $150 \mathrm{~mL}$ de solvente etanol absoluto. No processo a frio fora utilizado $150 \mathrm{~g}$ do pó das folhas de A. blanchetti, imerso em $150 \mathrm{~mL}$ de etanol absoluto durante $72 \mathrm{~h}$. Após o procedimento os extratos (a quente e a frio) foram reduzidos em evaporador rotativo por $2 \mathrm{~h}$ a 78 ${ }^{\circ} \mathrm{C}$ (BEZERRA-SILVA et al., 2010; GOMES, 2011) e armazenados a temperatura ambiente.

\section{Obtenção do isolado e determinação da concen- tração de esporos}

O isolado de $A$. brassicicola foi obtido de folhas de couve-manteiga com sintomas de alternari- 
ose. O método de isolamento utilizado foi o descrito por Alfenas et al. (2007). Após a obtenção do isolado este foi multiplicado colocando-se pequenas quantidades de conídios em placas Petri contendo meio de cultura BDA esterilizado. As placas foram mantidas a $25^{\circ} \mathrm{C}$ por um período de sete dias. Após esse período, o patógeno foi inoculado com suspensão de esporos na concentração de $1 \times 10^{5}$ esporos $\mathrm{mL}^{-1}$ em plantas sadias de couve-manteiga, sendo reisolado após o surgimento dos primeiros sintomas da doença.

Para o cálculo da concentração de esporos 20 $\mathrm{mL}$ de água destilada esterilizada foram adicionadas em placas contendo o inóculo e efetuada a raspagem das colônias e filtragem em camada dupla de gaze esterilizada. Em seguida, foi determinada a concentração de esporos a partir da contagem em câmara de Neubauer.

\section{Influência dos extratos de $A$. blanchetti na severi- dade da alternariose da couve-manteiga}

As sementes de couve-manteiga foram semeadas em vasos plásticos contendo $195 \mathrm{~g}$ de areia e esterco bovino, na proporção $2: 1$. O experimento foi conduzido em casa de vegetação, localizada no Campus de Juazeiro, Bahia, da Universidade Federal do Vale do São Francisco. Sete dias após a semeadura foi realizado o desbaste, mantendo-se uma muda por vaso. As regas foram efetuadas uma vez por dia. Aos 60 dias após a germinação deu-se início a aplicação dos seguintes tratamentos: (1) pulverização com água destilada esterilizada (concentração 0); (2) pulverização com extrato bruto de $A$. blanchetti, extraído a quente, na concentraçao de 100 ppm; (3) pulverização com extrato bruto, extraído a quente, na con- centraçao de 500 ppm; (4) pulverização com extrato bruto, extraído a quente, na concentraçao de 1000 ppm; (5) pulverização com extrato bruto, extraído a frio, na concentraçao de 100 ppm; (6) pulverização com extrato bruto, extraído a frio, na concentracao de 500 ppm; (7) pulverização com extrato bruto, extraído a frio, na concentracao de 1000 ppm. A pulverização das mudas foi efetuada com $40 \mathrm{~mL}$ de extrato.

Após $24 \mathrm{~h}$ foi realizada a pulverização das mudas com a suspensão de esporos de A. brassicicola a uma concentração de $1 \times 10^{5}$ esporos $\mathrm{mL}^{-1}$. Os dois procedimentos foram efetuados ao final da tarde, quando ocorre a abertura dos estômatos. Nas soluções dos tratamentos e na suspensão de esporos foram adicionadas $1,5 \mathrm{~mL}$ de espalhante adesivo Tween 80 para permitir uma aplicação mais uniforme. As mudas, após serem inoculadas, foram mantidas em câmara úmida durante 48 h.

As avaliações da severidade da doença foram efetuadas todos os dias, iniciando-se com o surgimento dos sintomas, cinco dias após a inoculação, e estendendo-se até a estabilização dos sintomas, ou seja, quando não houve mais evolução da doença, o qual ocorreu ao décimo dia após a inoculação, totalizando seis dias de avaliação.

A severidade da doença foi estimada com o auxilio de escala diagramática indicando notas de 0 a 50 (CONN; TEWARI; AWASTHI, 1990), com a nota 0 indicando ausência de sintomas e 50 para severidade máxima. Os dados foram transformados em porcentagem utilizando a equação do índice de infecção de Mckinney (1923).
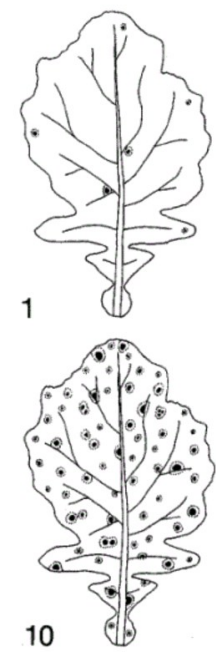
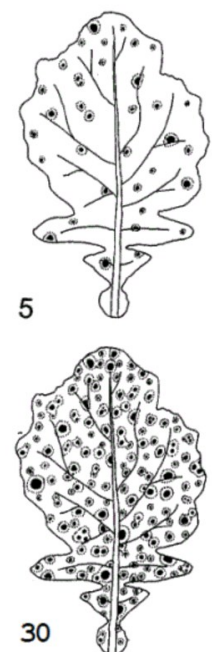
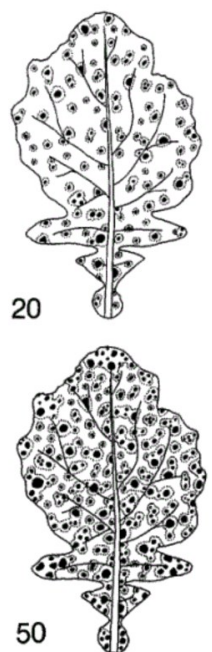

Figura 1. Escala diagramática de notas de alternariose em couve (CONN; TEWARI, J. P.; AWASTHI, 1990)

A área abaixo da curva de progresso da doença (AACPD) de cada repetição (cinco mudas por tratamento) foi calculada utilizando-se os valores do índice de infecção.
O delineamento experimental utilizado foi o fatorial $2 \times 4$, com dois métodos de extração (quente e frio) $x$ quatro concentrações $(0 ; 100 ; 500$ e 1000 ppm), com cinco repetições por tratamento, sendo 
cada repetição constituída por uma muda. Os dados da AACPD foram submetidos à análise de variância (ANOVA). Havendo significância na ANOVA $(\mathrm{P}<0,05)$, o fator qualitativo (métodos de extração) foi analisado por meio de teste de comparação de médias de Scott-Knott $(\mathrm{P}<0,05)$ e o fator quantitativo (concentrações) foi submetido a análise de regressão. As análises foram realizadas através do software Assistat (ASSISTAT, 2010).

Determinação da atividade de Peroxidase em mudas de couve-manteiga tratadas com extratos de A. blanchetti

Amostras de 0,5 g de folhas na posição mediana das plantas de couve-manteiga foram coletadas as $0,24,72,120$ e $168 \mathrm{~h}$ após a aplicação dos tratamentos. Os tempos de coletas das folhas foram adaptados da metodologia adotada por Pereira et al. (2009) e por Gomes (2011). As amostras das folhas foram coletadas conforme o seguinte esquema: $0 \mathrm{~h}=$ antes da aplicação dos tratamentos e da inoculação; $24 \mathrm{~h}=$ coletadas $24 \mathrm{~h}$ após a aplicação dos tratamentos e antes da inoculação; $72 \mathrm{~h}=$ coletadas $72 \mathrm{~h}$ após a aplicação dos tratamentos e $48 \mathrm{~h}$ após a inoculação; $120 \mathrm{~h}=$ coletadas $120 \mathrm{~h}$ após a aplicação dos tratamentos e $96 \mathrm{~h}$ após a inoculação; e $168 \mathrm{~h}=$ coletadas $168 \mathrm{~h}$ após a aplicação dos tratamentos e $144 \mathrm{~h}$ após a inoculação.

As amostras foram armazenadas em freezer a $-20{ }^{\circ} \mathrm{C}$. Oito dias após a primeira coleta as amostras de folhas foram pesadas e maceradas na presenca de nitrogênio líquido, usando almofariz e pistilo e, em seguida, homogeneizadas com $5 \mathrm{~mL}$ de tampão acetato de sódio a $100 \mathrm{mM}$ (com EDTA a $1 \mathrm{mM}$, PVP a $1 \%$ da solução tampão e $\mathrm{pH} 5,0$ ). A solução resultante foi transferida para microtubos de $1,5 \mathrm{ml}$ e centrífugada a $20000 \mathrm{~g}$ durante 25 minutos a $4{ }^{\circ} \mathrm{C}$ (COUTO et al., 2009). Uma vez centrifugada, a solução sobrenadante, considerada como extrato enzimático, foi transferida para novos tubos e armazenada novamente em freezer a $-20{ }^{\circ} \mathrm{C}$.

A determinação da atividade de peroxidase foi baseada na metodologia utilizada por Couto et al. (2009), utilizando-se $25 \mu \mathrm{L}$ de guaiacol a $20 \mathrm{mM}$ e 1,0 mL de tampão acetato de sódio a $100 \mathrm{mM}$; pH5,0. Após adição de $0,25 \mathrm{~mL}$ de peróxido de hidrogênio a $380 \mathrm{mM}$ a mistura foi agitada manualmente e utilizada como branco na análise espectrofotométrica dos tratamentos. Para comparação com o branco fora acrescentado $0,5 \mathrm{~mL}$ do extrato enzimático, sendo esta solução rapidamente submetida à leitura no comprimento de onda de $470 \mathrm{~nm}$ por 60 segundos.

Os resultados foram divididos pelo peso das amostras de folhas das mudas de couve-manteiga. A atividade de peroxidase foi expressa em unidade de absorbância $\min ^{-1} \mathrm{~g}^{-1}$ de peso fresco. E os dados analisados por meio de estatística descritiva, através do software Assistat (ASSISTAT, 2010).

\section{Influência dos extratos de $A$. blanchetti na inibi- ção da germinação dos esporos de $\boldsymbol{A}$. brassicicola}

As avaliações do efeito de ação direta dos dois extratos de $A$. blanchetii (a quente e a frio) sobre o fungo $A$. brassicicola foram efetuadas com base na metodologia adotada por Bonaldo et al. (2004). Foram utilizadas alíquotas preparadas pela mistura de $40 \mu \mathrm{L}$ da suspensão de esporos $\left(1 \times 10^{5}\right.$ esporos $\left.\mathrm{mL}^{-1}\right)$ e $40 \mu \mathrm{L}$ de cada concentração do extrato: $0 ; 100 ; 500$; e $1000 \mathrm{ppm}$. Cada alíquota foi colocada em um dos 96 poços de placas de microtitulação descartável com 96 poços, fundo chato, sem tampa e estéril. As placas foram incubadas em BOD durante 20 horas, sob iluminação constante e temperatura de $25{ }^{\circ} \mathrm{C}$. Ao término desse tempo, a germinação foi paralisada pela adição de $20 \mu \mathrm{L}$ do corante azul de lactofenol.

As avaliações foram realizadas em microscópio óptico, com aumento de 400 vezes. As alíquotas de cada poço foram transferidas para a câmara de Neubauer, sendo realizada a contagem média dos esporos nos dois campos da câmara, germinados e não germinados, obtendo-se a porcentagem de esporos germinados, em oito repetições por tratamento. Foram considerados como esporos germinados aqueles que apresentavam tubo germinativo de tamanho igual ou superior ao comprimento do esporo.

$\mathrm{O}$ delineamento experimental utilizado foi o fatorial $2 \times 4$, com dois métodos de extração (quente e frio), quatro concentrações $(0,100,500$ e 1000 ppm) e oito repetições, sendo cada repetição constituída por uma alíquota. Os dados foram submetidos à análise de variância (ANOVA). Havendo significância na ANOVA $(\mathrm{P}<0,05)$ o fator qualitativo (métodos de extração) foi analisado por meio de teste de comparação de médias de Scott-Knott $(\mathrm{P}<0,05)$ e o fator quantitativo (concentrações) submetido a análise de regressão. As análises foram realizadas através do software Assistat (ASSISTAT, 2010).

\section{RESULTADOS E DISCUSSÃO}

\section{Influência dos extratos de $\boldsymbol{A}$. blanchetti na severi- dade da alternariose da couve-manteiga}

Não houve diferença significativa entre os métodos de extração (quente e frio) e entre a interação métodos de extração x concentrações $(\mathrm{P}>0,05)$. No entanto, o efeito principal das concentrações foi significativo $(\mathrm{P}<0,05)$ (Tabela 1$)$. $\mathrm{O}$ mesmo foi submetido a análise de regressão (Figura 2). 
J. S. G. BARROS et al.

Tabela 1. Análise de variância dos dados de Área Abaixo da Curva de Progresso da Doença (AACPD).

\begin{tabular}{ccccc}
\hline Fator de Variação & GL & SQ & QM & F \\
\hline Métodos de extração & 1 & 4202,5 & 4202,5 & $0,4034 \mathrm{~ns}$ \\
Concentrações & 3 & 121514,5 & 40504,8 & $3,888 *$ \\
Métodos de extração x Concentrações & 3 & 3339,7 & 1113,23 & $0,1069 \mathrm{~ns}$ \\
\hline
\end{tabular}

*Significativo ao nível de $5 \%$ de probabilidade, de acordo com o teste $\mathrm{F}$.

Através da análise de regressão (Figura 2) verifica-se que a AACPD apresentou uma tendência linear decrescente em relação às concentrações do extrato de $A$. blanchetti. Isso indica que a severidade da doença em mudas de couve-manteiga reduziu com o aumento da concentração dos extratos (a quente e a frio).

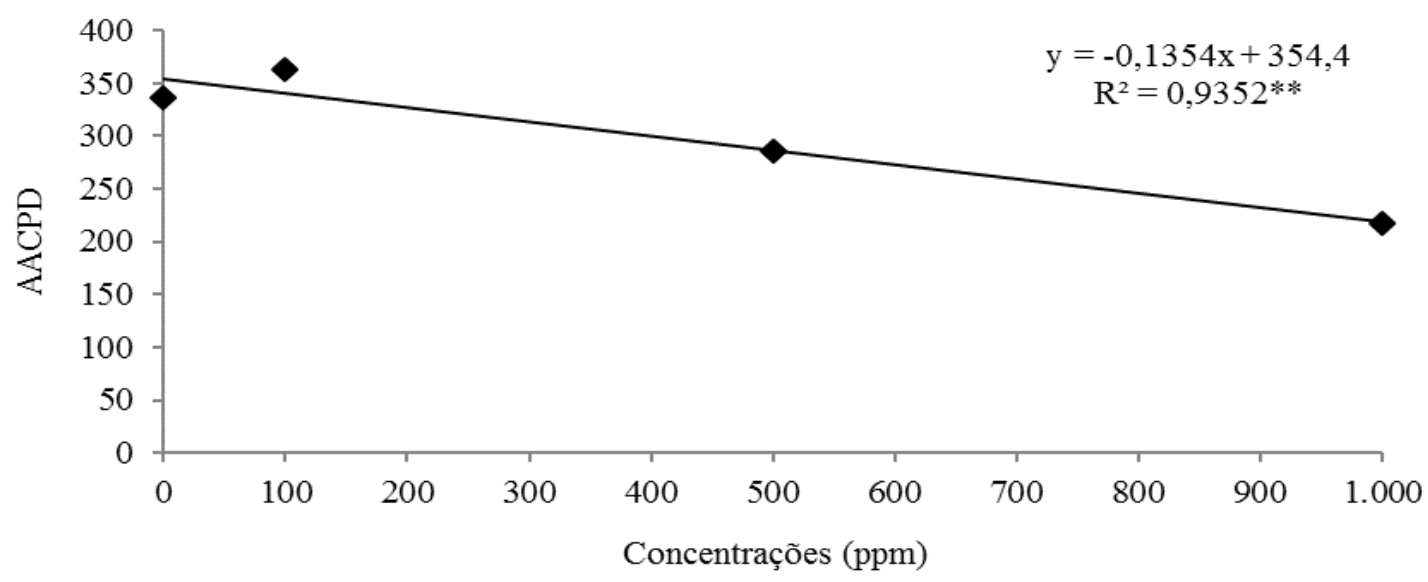

Figura 2. Curva de regressão dos dados de área abaixo da curva de progresso da doença (AACPD) ajustada para as concentrações $0,100,500$ e $1000 \mathrm{ppm}$ do extrato de $A$. blanchetti. ${ }^{* *}$ Significativo ao nível de $1 \%$ de probabilidade. A concentração 0 ppm representa a testemunha água $(\mathrm{CV} \%=34)$.

As concentrações mais elevadas dos extratos de $A$. blanchetti (1000 ppm a quente e a frio) foram mais eficientes no controle do patógeno, proporcionando maior redução da severidade da doença, com índices de proteção de 30,0 e 40,4\%, respectivamente (Figura 3). O nível de proteção observado neste estudo para o extrato a $1000 \mathrm{ppm}$ a frio foi semelhante ao obtido por Souza et al. (2015), que ao avaliarem o efeito de extrato vegetal de Momordica charantia no controle da podridão negra em abacaxi causada por |Chalara paradoxa L. obteve nível de proteção de $42,59 \%$ para a maior concentração do extrato avaliada (1000 ppm).

Os resultados apresentados na Tabela 1 e Figura 2 demonstram que o aumento das concentrações dos extratos foi o fator determinante para o controle da Alternariose causada pelo fungo A . brassicicola em mudas de couve-manteiga. Resultado semelhante também foi observado por Araújo et al. (2013), os quais verificaram que o extrato de $A$. blanchetti reduziu a incidência do fungo Aspergillus niger em sementes de Enterolobium contortisiliquum na maior concentração estudada (1000 ppm). Medeiros et al. (2012) obtiveram redução significativa na incidência de Cladosporium sp., Aspergillus sp., Rhizopus sp., Penicillium sp., Nigrospora sp. e Pestalotia sp. em sementes de Caesalpinia pulcherrima L., com extratos a $1000 \mathrm{ppm}$ de $A$. cathartica. E
Souza et al. (2015) também verificaram menor incidência da podridão negra no abacaxi com o aumento da concentração do extrato de Momordica charantia.

No entanto, apesar do método de extração não ter apresentado efeito significativo, o extrato a frio a 1000 ppm conferiu índice de proteção numericamente maior em mudas de couve em relação ao extrato a quente da mesma concentração $(40,4 \%$ e $30 \%$, respectivamente). Este resultado corrobora com o encontrado por Gomes (2011), que ao estudar o efeito do extrato a quente e a frio de $A$. blanchetti no controle de Uncinula necator em plantas de videira (Superior Seedless) também verificou maior controle da doença nos extratos a quente e a frio a 1000 ppm, com maior nível de proteção obtido pelo extrato a frio (55\% de proteção no extrato a quente e $62,1 \%$ de proteção no extrato a frio).

A redução da incidência da doença observada nas concentrações mais elevadas dos extratos indica que as mesmas possuem maior concentração de substâncias elicitoras, o que possibilita a sinalização de respostas de defesas mais eficientes nas plantas tratadas, promovendo a ativação de genes relacionados com a síntese de proteínas-PR, enzimas integrantes de rotas de fitoalexinas e mecanismos de defesa estruturais como, por exemplo, a enzima peroxidase (CAVALCANTI; BRUNELLI; STANGARLIN, 2005). 

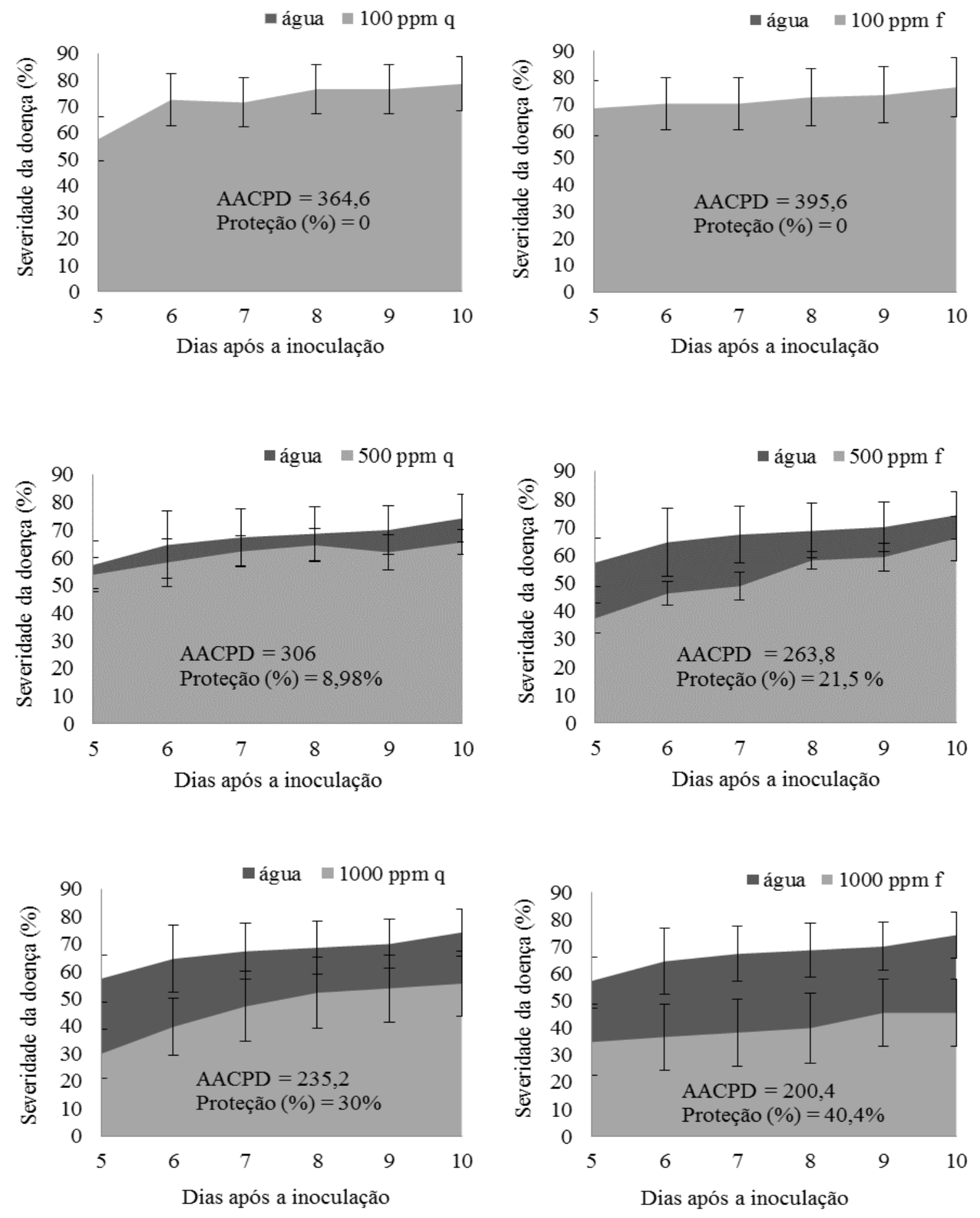

Figura 3. Severidade da doença causada por $A$. brassicicola em mudas de couve-manteiga tratadas com extrato de $A$. blanchetti extraído a quente(q) e a frio (f), nas concentrações de 100, 500 e 1000 ppm. A testemunha foi obtida pela aplicação de água destilada esterilizada.

Atividade de peroxidase em mudas de couve-manteiga tratadas com extratos de $A$. blanchetti

Um pico de atividade da peroxidase do extrato a frio ocorreu $24 \mathrm{~h}$ após a aplicação dos tratamen- tos nas concentrações de 500 e 1000 ppm, antes da inoculação, diferindo da testemunha água (Figura 4B). Na concentração de 100 ppm a frio ocorreu um pico de peroxidase $120 \mathrm{~h}$ após a aplicação do extrato. No entanto não houve redução da severidade da doença para esta concentração. 
Quanto ao extrato a quente, apesar de não ter apresentado diferença estatística entre os tratamentos houve maior atividade da concentração de 1000 ppm em relação às demais concentrações, $24 \mathrm{~h}$ após a aplicação dos tratamentos (antes da inoculação) (Figura 4A).
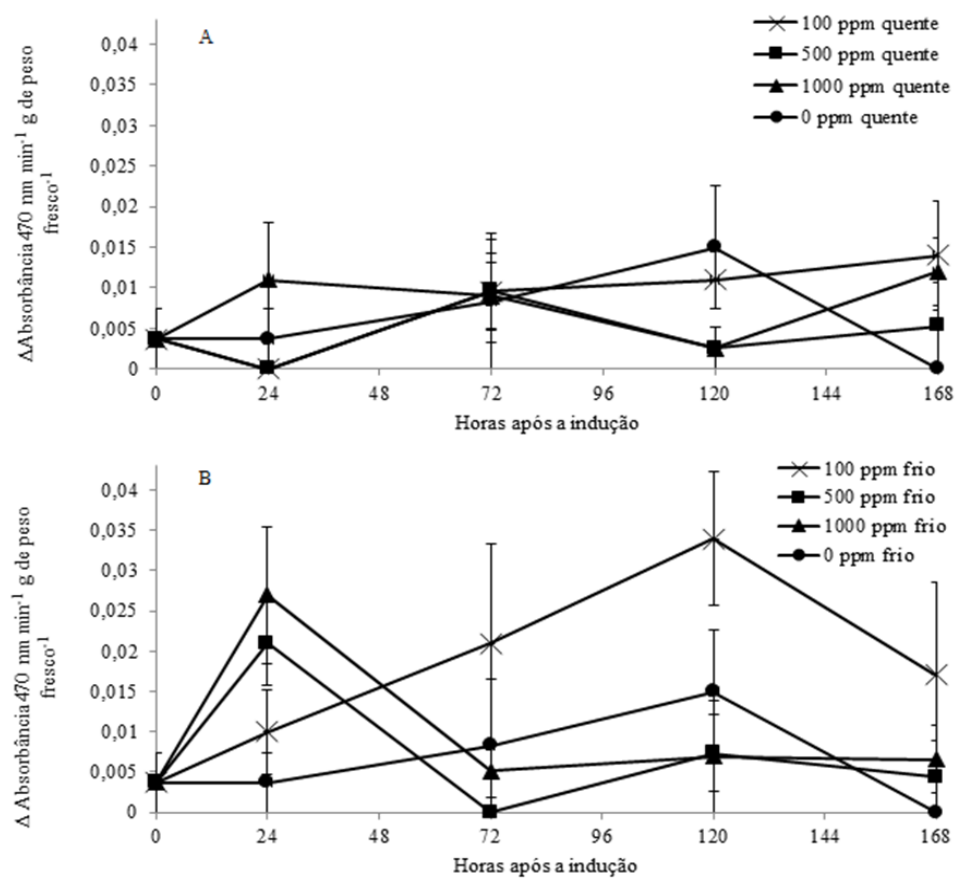

Figura 4. Atividade de peroxidases para os extratos de $A$. blanchetti a quente (A) e a frio (B) em mudas de couve-manteiga, às $0,24,72,120$ e 168 horas após a indução. A inoculação com o fungo $A$. brassicicola ocorreu 24 horas após a indução. 0 hora após a indução representa as mudas na condição inicial (sem extrato e sem patógeno). E as barras de erro indicam desvio-padrão das médias.

Este resultado sugere que o extrato a frio a $1000 \mathrm{ppm}$ promoveu maior controle da doença nas mudas de couve $(40,4 \%)$ devido a ativação da peroxidase antes da inoculação do patógeno, inibindo a penetração do fungo através do estabelecimento de barreiras físicas na parede celular das folhas. As peroxidases catalisam a oxidação de álcoois fenólicos à lignina promovendo modificações na parede celular, conferindo-a maior resistência a ataques de enzimas hidrolíticas e aumentando a resistência das paredes contra a difusão de toxinas liberadas pelos patógenos (CAVALCANTI; BRUNELLI; STANGARLIN, 2005; RESENDE et al., 2007).

De acordo com Bonaldo, Pascholati e Romeiro (2005), quanto mais rápido a planta reconhece a presença da molécula elicitora maior será a proteção da mesma ao patógeno. Pereira et al. (2008) também verificaram relação entre a redução da severidade de murcha-de-verticílio em cacaueiro e aumento na atividade de peroxidases, no qual os tratamentos que obtiveram maior controle desta doença, ASM e filltrado de micélio de Rhizopus sp. também apresentaram picos de atividade de peroxidases superiores ao tratamento controle.

Cavalcanti, Resende e Oliveira (2007), ao estudarem o extrato aquoso a frio de Crinipellis perniciosa obtido de Solanum lycocarpum, verificaram redução significativa de $42,5 \%$ do progresso da mancha foliar bacteriana (Xanthomonas campestris pv. vesicatoria), quando previamente pulverizado em folhas de tomateiro, e constataram que as frações obtidas deste extrato por precipitação salina e cromatografia de troca iônica foram capazes de elicitar a atividade de peroxidase 14 horas após a pulverização das plantas. Gomes (2011) verificou que o extrato etanólico de $A$. blanchetti obtido a frio na concentração de 1000 ppm promoveu o aumento na atividade das enzimas fenilalanina amônia-liase, peroxidase e $\beta$-1,3-glucanase. No entanto, não houve relação entre os níveis de controle de Uncinula necator em videira e aumento na atividade de peroxidases promovido pelos extratos a quente e a frio de $A$. blanchetti.

Alguns autores relatam que as peroxidases não podem ser utilizadas como marcador de resistência para alguns patossistemas por não apresentarem relação direta com o estabelecimento da indução de resistência, mas afirmam também que a alteração na sua atividade é um indício de metabolismo alterado, como formação de lignina e alteração de outras enzimas presentes na mesma rota metabólica (BOAVA et al., 2010). Para Stangarlin et al. (2011), a ativação de peroxidases é um indício de indução de resistência, haja vista que estas enzimas atuam na ação preventiva contra a penetração de patógenos por ação oxidativa de componentes da parede celular vegetal.

Influência de extratos de $A$. blanchetti na germinação dos esporos de $\boldsymbol{A}$. brassicicola 
Quanto a ação direta dos extratos sobre o patógeno (Tabela 2), a interação métodos de extração $\mathrm{x}$ concentrações foi significativa $(\mathrm{P}<0,01)$. Os resultados mostraram que os dois métodos de extração promoveram inibição da germinação dos esporos do fungo A. brassicicola com diferença significativa entre os extratos a quente e a frio nas concentrações de 100,500 e 1000 ppm. O extrato a quente apresentou os maiores índices de inibição da germinação, atingindo 98,23\% de inibição para a concentração de $1000 \mathrm{ppm}$.

Tabela 2. Inibição da germinação dos esporos de A. brassicicola (\%) promovida pelos extratos, obtidos a quente e a frio, de A. blanchetti.

\begin{tabular}{lcccc}
\hline \multirow{2}{*}{ Método de extração } & \multicolumn{4}{c}{ Concentrações (ppm) } \\
\cline { 2 - 5 } & $0^{(2)}$ & 100 & 500 & 1000 \\
\hline Extrato a quente & $4,62 \mathrm{a}^{1}$ & $50,05 \mathrm{a}$ & $87,11 \mathrm{a}$ & $98,23 \mathrm{a}$ \\
Extrato a frio & $4,62 \mathrm{a}$ & $27,00 \mathrm{~b}$ & $45,87 \mathrm{~b}$ & $70,61 \mathrm{~b}$ \\
\hline
\end{tabular}

${ }^{(1)}$ Médias seguidas pela mesma letra na coluna, para cada concentração, não diferem entre si pelo teste de Scott-Knott a 5 \% de probabilidade $(\mathrm{CV} \%=12,97) .{ }^{(2)} \mathrm{A}$ concentração zero se refere à testemunha água destilada esterilizada.

As curvas ajustadas demonstram que há uma tendência linear crescente entre as concentrações dos extratos a quente e a frio e a inibição da germinação dos esporos (Figura 5 A e B). Desta forma, o aumento da concentração dos extratos promoveu aumento da porcentagem de esporos não germinados. Este resultado também foi observado por Itako et al. (2008) para diferentes concentrações de extrato aquoso de Artemisia camphorata, Achillea millefolium, Cymbopogon citratus e Rosmarinus officinalis na germinação de conídios de Alternaria solani.

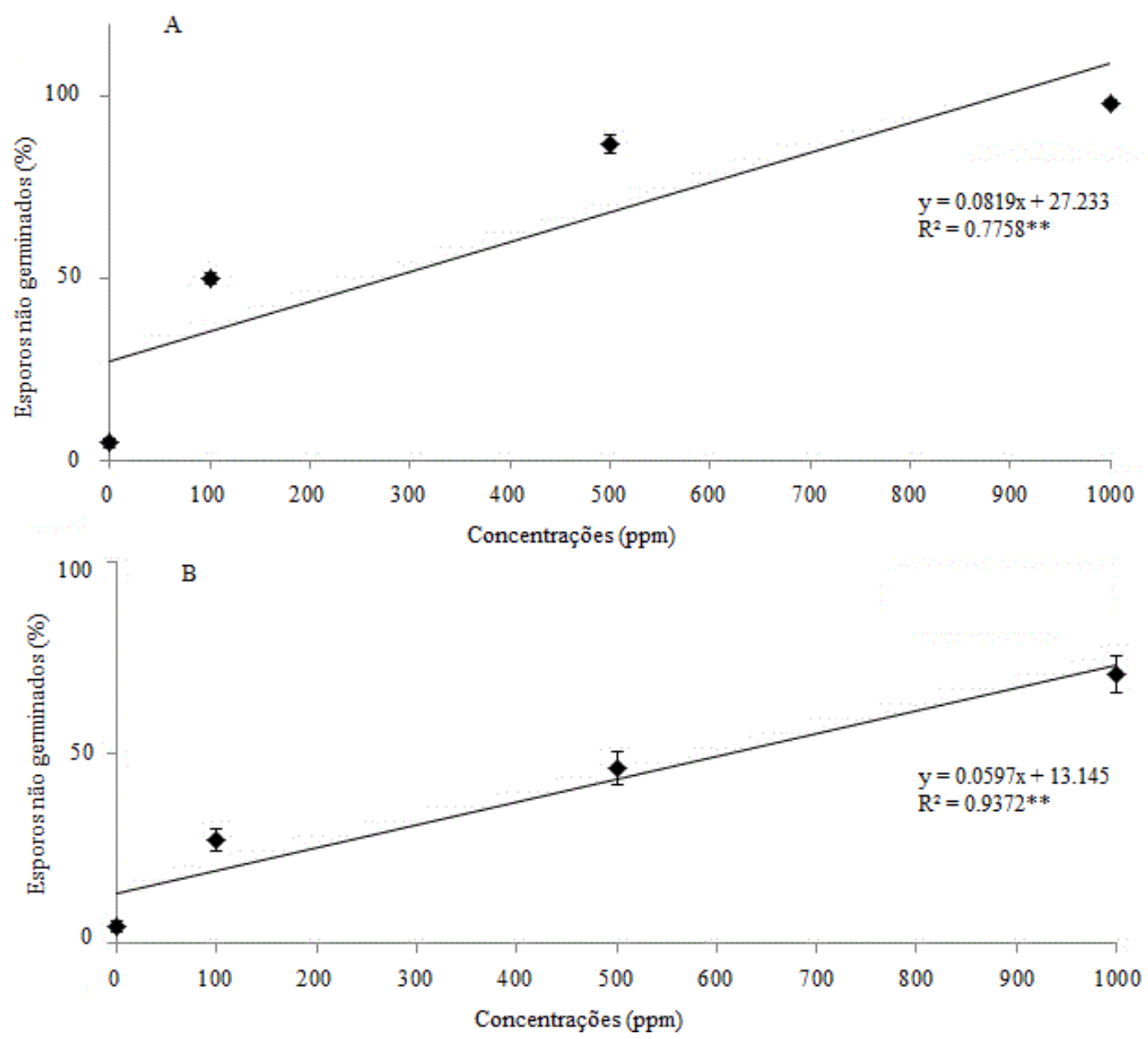

Figura 5. Curvas de regressão dos extratos de $A$. blanchetti extraído a quente (A) e a frio (B) em função das concentrações de $0,100,500$ e $1000 \mathrm{ppm}$. A concentração 0 ppm representa a testemunha água destilada esterilizada. ** Significativo ao nível de $1 \%$ de probabilidade. 
Os resultados apresentados na Tabela 2 e Figura 5 sugerem que o método de extração causou alteração na composição de substâncias com ação fungitóxica nos extratos de $A$. blanchetti. Nota-se que o extrato a frio não extraiu de forma eficiente as substâncias que inibiram a germinação dos esporos, sendo necessário uma concentração maior desse extrato para atingir grau completo de inibição. Longhini et al. (2007) também verificaram efeito do método de extração com diferentes líquidos extratores (etanol e propilenoglicol) na ação antifúngica dos extratos de própolis e no teor de flavonóides. BalbiPeña et al. (2006) verificaram diferença da ação fungitóxica entre os extratos autoclavados e não autoclavados de cúrcuma e de curcumina.

Substâncias com ação antifúngica foram identificadas em algumas espécies de Allamanda. Graebner (2003), ao avaliar os constituintes químicos de plantas medicinais, isolou substâncias com atividade antifúngica denominadas de iridóides das espécies de Allamanda cathartica e Allamanda schottii.

Estudos também têm demonstrado o potencial de extratos de Allamanda spp. no controle de patógenos vegetais. Medeiros et al. (2013), ao avaliarem o efeito de extrato vegetais na microflora de sementes de Clitoria fairchildiana, verificaram que o extrato de Allamanda blanchetti reduziu significativamente o crescimento do fungo Rhizopus stolonifer. Níveis significativos de controle de patógenos com o uso de extratos de Allamanda spp. também foram observados. Ahmed, Meah e Yasmin (2012) verificaram que extratos de Allamanda cathartica inibiram em 100\% o crescimento micelial de Phomopsis vexans. Em trabalho desenvolvido por Masuduzzaman, Meah e Rashid (2008), no qual fora avaliado o efeito das concentrações $1: 1,1: 2,1: 3$ e 1:4 de extrato aquoso de Allamanda, observaram que algumas destas concentrações foram eficientes no controle de fitopatógenos, inibindo completamente o crescimento micelial de alguns fitopatógenos, como Phomopsis vexans, Rhizoctonia solani (todas as concentrações), Sclerotium rolfsii e Phytophthora capsici. Domingues et al. (2009) verificaram inibição total do crescimento micelial de Colletotrichum acutatum pelo extrato de $A$. cathartica, mostrando sua atividade fungitóxica sobre este patógeno.

\section{CONCLUSÃO}

Os resultados indicam que os extratos de $A$. blanchetti são capazes de atuar na redução da severidade dos sintomas da alternariose em mudas de couve-manteiga, podendo atuar tanto na ativação de mecanismos de defesa como pela ação antimicrobiana direta sobre o patógeno.

\section{AGRADECIMENTOS}

À Financiadora de Estudos e Projetos (FINEP) e ao Conselho Nacional de Desenvolvimento Científico e Tecnológico (CNPq) pelo auxílio financeiro.

\section{REFERÊNCIAS}

AHMED, F.; MEAH, M. B.; YASMIN, F. Isolation of Phomopsis Inhibitory Fraction of Allamanda Extract. Journal Environment Science \& Natural Resources, Bangladesh, v. 5, n. 2, p. 199-203, 2012.

ALFENAS, A. C. et al. Isolamento de fungos fitopatogênicos. In: ALFENAS, A. C.; MAFIA, R. G. (Eds.). Métodos em fitopatologia. Viçosa: Ed. UFV, 2007, p. 53-90.

ARAÚJO, A. K. O. et al. Tratamento Alternativo no Controle de Fungos Associados a Sementes de Enterolobium contortisiliquum. Cadernos de Agroecologia, Porto Alegre, v. 8, n. 2, p. 1-4, 2013.

ASSISTAT. Versão 7.5 beta, Campina Grande PB. 2010.

AZEVÊDO, S. S.; MICHEREFF, S. J.; MARIANO, R. L. R. Levantamento da intensidade da podridão negra e da alternariose do repolho no Agreste de Pernambuco e determinação do tamanho das amostras para quantificação dessas doenças. Summa Phytopathologica, Jaboticabal, v. 26, n. 3, p. 299 306, 2000.

BEZERRA-SILVA, G. C. D. et al. Efeito de extratos orgânicos de Meliaceae sobre Bemisia tabaci (gennadius) biótipo $\mathrm{b}$ em tomateiro. Arquivos do Instituto Biológico, São Paulo, v. 77, n. 3, p. 477485, 2010.

BALBI-PEÑA, M. I. et al. Controle de Alternaria solani em tomateiro por extratos de Curcuma longa e Curcumina - II. Avaliação in vivo. Fitopatologia Brasileira, Brasília, v. 31, n. 4, p. 401-404, 2006.

BOAVA, L. P. et al. Efeito de indutores bióticos e abióticos na atividade de quitinase e peroxidase e no controle da ferrugem causada por Puccinia psidii em eucalipto. Summa Phytopathologica, Jaboticabal, v. 36, n. 2 , p. $168-172,2010$.

BONALDO, S. M.; PASCHOLATI, S. F.; ROMEIRO, R. S. Indução de resistência: noções básicas e perspectivas. In: CAVALCANTI, L. S. et al. (Eds.). Indução de Resistência em Plantas a Patógenos e Insetos. Piracicaba: FEALQ, 2005. p.11-28.

BONALDO, S. M. et al. Fungitoxicidade, atividade elicitora de fitoalexinas e proteção de pepino contra Colletotrichum lagenarium, pelo extrato aquoso de 
Eucalyptus citriodora. Fitopatologia Brasileira, Jaboticabal, v. 29, n. 2, p.128-134, 2004.

CAVALCANTI, L. S.; BRUNELLI, K. R.; STANGARLIN, J. R. Aspectos bioquímicos e moleculares da resistência induzida. In: CAVALCANTI, L. S. et al. (Eds.). Indução de Resistência em Plantas a Patógenos e Insetos. Piracicaba: FEALQ, 2005. p.11-28.

CAVALCANTI, F. R.; RESENDE, M. L. V.; OLIVEIRA, J. T. A. Peroxidases ativadas por frações protéicas de extrato biológico eficaz na proteção do tomateiro contra a mancha bacteriana. Fitopatologia Brasileira, Brasília, v. 32, n. 6, p. 507-511, 2007.

CONN, K. L.; TEWARI, J. P.; AWASTHI, R. P. A disease assessment key for Alternaria blackspot in rapessed and mustard. Canadian Plant Disease Survey, Ottawa, v. 70, n. 1, p 19-22, 1990.

COUTO, E. F. et al. A. Avaliação de indutores de resistência em algodoeiro a murcha de fusário: atividade enzimática e índice de infecção. Tropical Plant Pathology, Brasília, v. 34, n. 5, p. 352-356, 2009.

DOMINGUES, R. J. et al. Ação "in vitro" de extratos vegetais sobre Colletotrichumacutatum, Alternaria solani e Sclerotium rolfsii. Arquivos do Instituto Biológico, São Paulo, v. 76, n. 4, p. 643-649, 2009.

GOMES, E. C. S. Extrato de Allamanda blanchetti na indução de fitoalexinas em sorgo e resistência em videira 'Superior Seedless' contra Uncinula necator. 2011. 90 f. Tese (Doutorado em Agronomia: Área de Concentração em Agricultura Tropical) - Universidade Federal da Paraíba, Areias, 2011.

GRAEBNER, I. B. Estudos dos constituintes químicos isolados de plantas medicinais da região do Vale do Purus no Acre (Amazônia). 2003. 113 f. Tese (Doutorado em Química: Área de Concentração em Química Orgânica) -Universidade Federal de Santa Maria, Santa Maria, 2003.

IBGE. SIDRA: Horticultura. 2006. Disponível em: $<$ http://www.sidra.ibge.gov.br/bda/horti/default.asp? $\mathrm{z}=\mathrm{t} \& \mathrm{o}=19 \& \mathrm{i}=\mathrm{P}>$ Acesso em: 12 mar. 2015.

ITAKO, A. T. et al. Atividade antifúngica e proteção do tomateiro por extratos de plantas medicinais. Tropical Plant Pathology, Brasília, v. 33, n. 3, p. 241-244, 2008.

LEFSRUD M. et al. Chances in kale (Brassica oleracea L. var. acephala) carotenoid and chlorophyll pigment concentrations during leaf ontogeny. Scientia Horticulturae, Amsterdam, v. 112, n. 2, p.
136-141, 2007.

LONGHINI, R. et al. Obtenção de extratos de própolis sob diferentes condições e avaliação de sua atividade antifúngica. Brazilian Journal of Pharmacognosy, João Pessoa, v. 17, n. 3, p. 388-395, 2007.

MASUDUZZAMAN, S.; MEAH, M. B.; RASHID, M. M. Determination of inhibitory action of $\mathrm{Al}$ lamanda leaf extracts against some important plant pathogens. Journal of Agriculture \& Rural Development, Bangladesh, v. 6, n. 1, p. 107-112, 2008.

MCKINNEY, H. H. Influence of soil, temperature and moisture on infection of wheat seedlings by $\mathrm{Hel}$ minthosporium sativum. Journal of Agricultural Research, Washington, v. 26, p. 195-217, 1923.

MEDEIROS, J. et al. Fungos associados com sementes de flamboyant-mirim (Caesalpinia pulcherrima): incidência, efeito na germinação, transmissão e controle. Pesquisa Florestal Brasileira, Colombo, v. 32, n. 71, p. 303-308, 2012.

MEDEIROS, J. G. F. et al. C. Sanidade e germinação de sementes de Clitoria fairchildiana tratadas com extratos de plantas. Pesquisa Florestal Brasileira, Colombo, v. 33, n. 76, p. 403-408, 2013.

MICHEREFF, S. J. et al. Variabilidade de isolados de Alternaria brassicicola no Estado de Pernambuco. Fitopatologia Brasileira, Brasília, v. 28, n. 6, p. 656-663, 2003

MOREIRA, J. C. et al. Avaliação integrada do impacto do uso de agrotóxicos sobre a saúde humana em uma comunidade agrícola de Nova Friburgo, RJ Ciência \& saúde coletiva, São Paulo, v. 7, n. 2, p. 299-311, 2002.

NOVAIS, T. S. et al. Atividade antibacteriana em alguns extratos de vegetais do semi-árido brasileiro. Revista Brasileira de Farmacognosia, Maringá, v. 13, supl 2, p. 05-08, 2003.

NOVO, M. C. S. S. et al. Desenvolvimento e produção de genótipos de couve manteiga. Horticultura Brasileira, Brasília, v. 28, n. 3, p. 321-325, 2010.

PEREIRA, B. P. et al. Ativação de defesa em cacaueiro contra a murcha-de-verticílio por extratos naturais e acibenzolar-S-metil. Pesquisa Agropecuária Brasileira, Brasília, v. 43, n. 2, p. 171-178, 2008.

PEREIRA, S. C. et al. Aplicação foliar de silício na resistência da soja à ferrugem e na atividade de enzimas de defesa. Tropical Plant Pathology, Brasília, v. 34, n. 3, p. 164-170, 2009 
RESENDE, M. L. V. et al. Seleção de extratos vegetais para indução de resistência e ativação de respostas de defesa em cacaueiro contra a vassoura-debruxa. Fitopatologia Brasileira, Brasília, v. 32, p. 213-221, 2007.

SANTOS, F. S. et al. Efeito de extratos vegetais no progresso de doenças foliares do cafeeiro orgânico. Fitopatologia Brasileira, Brasília, v. 32, p. 59-63, 2007.

SILVA, C. P. et al. Desenvolvimento inicial de mudas de couve-folha em função do uso de extrato de alga (Ascophyllum nodosum). Revista Verde, Mossoró, v. 6, n. 1, p. 7-11, 2012.

SILVA, S. S. et al. Produção orgânica de mudas de couve-manteiga em substrato à base de coprolito de minhocas. Revista Caatinga, Mossoró, v. 20, n.4, p.78-83, 2007.

SOUZA et al. Alternative control of Chalara paradoxa, causal agent of black rot of pineapple by plant extract of Mormodica charantia. European Journal of Plant Pathology, Wageningen, v. 142, n. 3, p. 481-488, 2015.

STANGARLIN, J. R. et al. A defesa vegetal contra fitopatógenos. Scientia Agraria Paranaenis, Cascavel, v.10, n.1, p.18-46, 2011. 